\title{
Contaminação de solos por baterias Níquel-Hidreto metálico como tema motivador na feira de Ciências como estratégia de ensino
}

\author{
Storch, M. H.; Müller, R. A.; Neves, T. R.; Moura, P. R. G.; Vervloet, V. V.; \\ Freitas, M. B. J. G.; Ferreira, S. A. D.; Lelis, M. F. F.* \\ Departamento de Química, Universidade Federal do Espírito Santo, Vitória, ES, Brasil.
}

*e-mail: mfflelis@yahoo.com.br

\begin{abstract}
Resumo
O desenvolvimento da indústria eletroeletrônica tem trazido muitos benefícios à humanidade. $\mathrm{O}$ uso crescente de aparelhos portáteis, movidos a pilhas ou baterias, vem causando sérios impactos ambientais quando descartados junto ao lixo comum, devido a presença de metais em sua constituição. Este trabalho teve como objetivo abordar o tema "Pilhas e baterias" com enfoque na contaminação de solos por metais, a construção de conceitos científicos e o processo de ensino-aprendizagem com enfoque em abordagem CTSA (Ciência-Tecnologia-Sociedade-Ambiente). Foi utilizado o ambiente da feira de ciências, com a participação de estudantes de nível médio de uma escola estadual de ensino integral de Vitória, ES. A construção de uma coluna de solos permitiu verificar a lixiviação de níquel, presente em baterias de níquel-hidreto metálico pela reação de identificação do níquel como dimetilglioxima. $A$ feira de ciência contribuiu com a realização dos experimentos, a exploração dos conceitos científicos sobre composição química das pilhas e baterias, seu funcionamento e as consequências do descarte inadequado, além de desempenhar um importante papel social, incentivando o desenvolvimento de competências como liderança e trabalho em equipe.
\end{abstract}

Palavras Chave: ensino de química, feira de ciências, contaminação do solo.

\begin{abstract}
The development of the electronics industry has brought many benefits to humanity. The increasing use of portable, battery-powered appliances has been causing serious environmental impacts when disposed of with ordinary waste due to the presence of metals in its constitution. This work aimed to address the theme "Batteries" focusing on the contamination of soils by metals, the construction of scientific concepts and the teaching-learning process focusing on CTSA (Science-Technology-Society-Environment) approach. The science fair environment was used, with the participation of high school students from a state full-time school in Vitória, ES, Brazil. The construction of a soil column allowed the verification of nickel leaching, present in nickel-metal hydride. metal hydride by nickel identification reaction as dimethylglyoxime. The science fair contributed to the conduct of the experiments, the exploration of scientific concepts on the chemical composition of batteries, their operation and the consequences of improper disposal, as well as playing an important social role, encouraging the development of skills such as leadership and work in a team.
\end{abstract}


Keywords: chemistry Teaching, Science Fair, soil contamination.

\section{Introdução}

A preocupação ambiental em relação aos resíduos oriundos da indústria eletrônica vem crescendo muito nos últimos anos. A taxa de geração deste tipo de resíduo apresenta elevada tendência de crescimento em virtude do acelerado processo tecnológico e do descarte inadequado de aparelhos eletroeletrônicos, movidos a pilhas e baterias, que causam grandes impactos ambientais. A necessidade do ensino de química ambiental para o ensino médio, aliada aos problemas ambientais e sobre a natureza do conhecimento científico e seu papel na sociedade, cresceu no mundo inteiro. De acordo com os Parâmetros Curriculares Nacionais (PCNs), a articulação entre a Química e suas aplicações aliada aos impactos sociais, ambientais, políticos e econômicos dentro de um contexto de ensino médio, pode contribuir para o crescimento de uma cultura científica entre os jovens, permitindo a participação ativa dos mesmos naquilo que os permeiam. Um currículo com ênfase em CTSA se caracteriza pela integração entre educação científica, tecnológica, social e ambiental, centrada na inter-relação entre a explicação científica e a tomada de decisão sobre temas práticos de importância social ${ }^{[1-4]}$. A preocupação do professor é inserir e desenvolver o tema na disciplina por meio da criação de espaços e oportunidades que possibilitem o diálogo entre os sujeitos e os problemas ambientais.

O principal objetivo desse trabalho foi abordar de forma contextualizada a contaminação de solos com metais provenientes de pilhas e baterias descartadas no lixo comum. Os aspectos relacionados aos problemas ambientais, tipo de material, composição química, parâmetros de toxicidade e os riscos a saúde e ao meio ambiente foram explorados e discutidos. De acordo com a resolução do Conselho Nacional do Meio Ambiente (CONAMA) ${ }^{[5]}$ as pilhas e baterias que contém chumbo, cádmio, mercúrio e seus derivados, deverão ser devolvidas aos locais de venda. No Brasil existem muitos pontos de coleta, mas a falta de uma política eficiente de coleta em muitas localidades faz com que muitas pilhas e baterias sejam descartadas junto ao lixo comum, indo parar nos lixões. Com o tempo, os constituintes são liberados para o meio ambiente e, durante o contato com líquidos, são percolados ou lixiviados no perfil do solo, podendo ficar retidos ou contaminar o lençol freático ${ }^{[6]}$.

Além da contaminação do solo e das águas, o problema perpassa pela biodisponibilidade que esses metais apresentam. Podem ser encontrados na forma solúveis, com maior biodisponibilidade, como formas mais facilmente absorvidas pelas plantas, ou lixiviadas, podendo atingir as águas subterrâneas ${ }^{[6,7]}$. Com relação ao níquel, objeto de estudo neste trabalho, não são absorvidos pela pele em quantidades suficientemente tóxicas, mas a dermatite (uma reação de sensibilização da pele) é o efeito mais comum causado pela exposição direta ao metal ${ }^{[8]}$.

A alternativa que surge para reduzir o impacto ambiental pelo uso de pilhas e baterias é sua substituição por pilhas alcalinas ou baterias recarregáveis, que prologam seu tempo de uso ${ }^{[8,9]}$.

Os conhecimentos científicos aliados a problemática ambiental da contaminação proveniente do descarte incorreto de pilhas e baterias e suas consequências ao meio ambiente, foram utilizados na criação do ambiente da feira de ciências. Por meio da pesquisa, montagem do experimento e exposição dos resultados a comunidade, os alunos são levados a autonomia, com a proximidade do tema ao cotidiano.

As feiras de ciências são possibilidades de promover a integração entre professor e aluno, bem como escola e comunidade. Elas aproximam o conteúdo teórico abordado em sala de aula aos temas do meio CTSA de forma pertinente. São eventos realizados nas escolas com a intenção de oportunizar um diálogo de conhecimento, metodologia de pesquisa e criatividade. Garante também a oportunidade dos alunos deixarem a posição passiva no processo de aprendizagem. Nesse sentido, o processo passa a ser socializador e deve ser entendido como fruto do trabalho coletivo, no qual há interação entre os alunos, o meio e os recursos ${ }^{[10,11]}$.

Dentro dessa concepção, as feiras de ciências apresentam caráter interdisciplinar/multidisciplinar e de contextualização. Esta última consiste em atribuir significado ao que é vivido, aproximar o aluno ao problema tratado. A experimentação é uma forma de contextualização. Já a interdisciplinaridade se constitui de uma integração de conteúdos, provocando o trabalho cooperativo entre professores de diversas áreas. ${ }^{[12]}$

Existem muitas vantagens para investir na aprendizagem por projeto, universo o qual a feira de ciências se insere. Além de despertar a curiosidade e o interesse do aluno, a própria prática é motivadora. O aluno se sente à vontade para experimentar. $\mathrm{E}$ ao final, confrontando o saber cotidiano, o aluno tem novos posicionamento e um saber mais científico. Dentro dessa mesma perspectiva, os trabalhos em equipe favorecem a criticidade, a reflexão e a atuação na comunidade. Os alunos trocam informações entre si, experimentam e discutem os resultados de modo que, ao final, possam tirar conclusões construindo referências para a vida a partir da prática ${ }^{[11]}$. O fator limitante para realização das feiras de ciências é o 
tempo ou falta de materiais didáticos que, por vezes, geram dificuldades em sua realização. A falta de infraestrutura que muitas escolas apresentam podem ainda ser um agravante nesse quadro. Não obstante, a realização das feiras de ciências requer planejamento e engajamento dos docentes para realizá-la de forma multidisciplinar, o que seria ideal. Ademais, por meio delas, os alunos se sentem mais engajados e valorizados perante a escola e a comunidade ${ }^{[12]}$.

O presente trabalho aborda a contaminação de solos por meio do descarte inadequado de pilhas e baterias como tema gerador e problematizador associando a experimentação e a exposição dos resultados obtidos num contexto de feira de ciências por alunos da primeira série do ensino médio.

\section{Metodologia}

A amostra de solo coletada na região da grande Vitória (ES), caracterizada como Latossolo vermelho amarelo argiloso foi desagregada manualmente, seca ao ar e passada em peneira de $2,0 \mathrm{~mm}$ de diâmetro para a obtenção da terra fina seca ao ar (TFSA), utilizada na montagem das colunas. Desmantelou-se uma bateria de Níquel-Hidreto metálico totalmente descarregada para obtenção de material que foi introduzido no meio da coluna de solo. Em seguida, foram montadas três colunas (Figura 1).

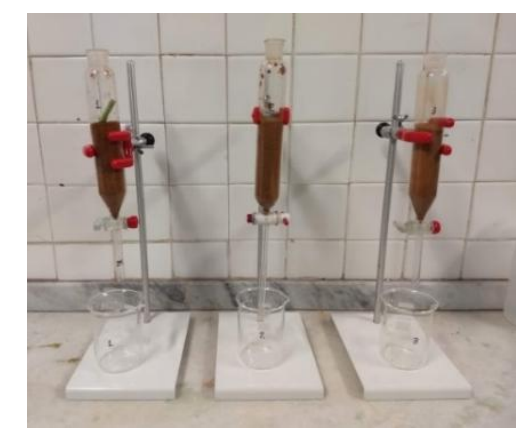

Figura 1: As três colunas de cromatografia contendo solo. Da esquerda para a direita, colunas 1,2 e 3.

$\mathrm{Na}$ coluna 1 foi adicionado o material obtido do desmantelamento da bateria; na coluna 2, adicionou-se nitrato de níquel e na coluna 3 apenas o solo. Completou-se cada coluna com água destilada e deixou em repouso. Após uma hora, coletou-se a primeira alíquota de amostra lixiviada. Uma solução tampão de ácido acético/acetato de sódio $(\mathrm{pH}=5,0)$ foi adicionada para completar toda a proveta, preenchendo as colunas de solo. Foram coletadas semanalmente, durante cinco semanas, amostras lixiviadas em cada uma das colunas. A amostra retirada foi submetida a análise qualitativa de níquel pela reação de identificação com dimetilglioxima (DMG), em meio básico, utilizando solução de hidróxido de sódio diluída ${ }^{[13]}$. Após retirada de cada alíquota, a coluna era novamente completada com solução tampão de ácido acético/acetato de sódio $(\mathrm{pH}=5,0)$.

\section{Discussão dos resultados}

Antes da montagem das colunas de solo, os alunos foram instruídos a realizarem uma pesquisa. O tema gerador foi inserido fomentando a discussão a respeito da questão ambiental e social. A pesquisa sobre o descarte incorreto de pilhas e baterias, a legislação brasileira referente a esse tipo de resíduo e os malefícios dos metais pesados em nossos organismos. Esses temas são importantes para contextualizar, a experimentação e explorar conhecimento científico. O material disponível aos alunos na forma de roteiro orientador continha perguntas, com enfoque ambiental: "O que são metais tóxicos?" "Quais são os malefícios da contaminação do solo por metais provenientes do descarte incorreto de pilhas e baterias?".

Os conceitos de lixiviação e análise qualitativa de níquel com DMG, considerados conteúdos de maior complexidade para a primeira série do ensino médio, foram introduzidos de forma contextualizada associada as observações e análise das amostras durante a realização do experimento de lixiviação. No período de cinco semanas houve a coleta de cinco amostras, sendo uma por semana. O uso da solução tampão de ácido acético e acetato de sódio foi necessário para promover a lixiviação ácida do material da bateria. A coluna foi deixada em repouso durante uma semana. Os alunos podiam comparar a cada semana, os resultados apresentados pelas as amostras de cada coluna de solo. As amostras retiradas da coluna 3 não apresentaram nenhuma reação com adição de DMG. Para a realização do teste de identificação de níquel, era necessário adicionar antes de DMG, solução diluída de hidróxido de sódio para corrigir o $\mathrm{pH}$ da solução. Inicialmente verificou-se uma cor esverdeada devido a presença de sais de níquel hidratados, conforme Figura 2.

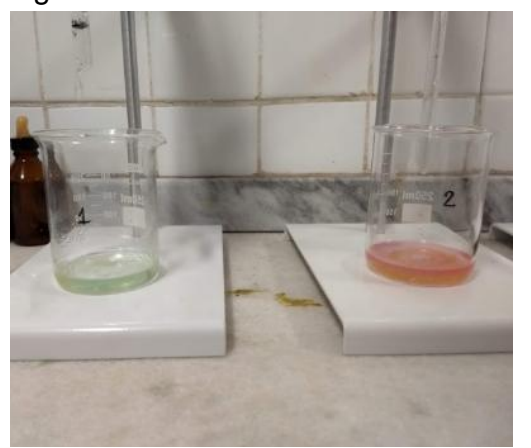

Figura 2: Solução 1 (solução lixiviada da coluna com a bateria de niquel-hidreto metálico); Solução 2 já com adição de DMG.

A Equação 1 demonstra a reação ocorrida entre o níquel e o DMG com a formação do complexo rosáceo sólido ${ }^{[13]}$. 


$$
N i^{2+}+2 \mathrm{H}_{2} \mathrm{DMG} \rightleftharpoons \mathrm{Ni}(H D M G)_{2}(s)+2 \mathrm{H}^{+}(1)
$$

Cada grupo de alunos foi responsável pela coleta das amostras e realização dos testes de identificação. Os alunos do PIBID (Programa Institucional de Bolsa de Iniciação a Docência) participaram junto aos alunos de todo o processo, no sentido de contribuir com o desenvolvimento do processo de ensino-aprendizagem. O grupo percebeu que a cada amostra retirada da coluna 1 , a cor rósea se acentuava. Isto se deve ao níquel proveniente da bateria lixiviado através do solo. Ao compararem as colunas 1 e 2 , observaram que 0 sal de níquel, biodisponibilizado, acarreta maior dano ao solo e, consequentemente, ao meio ambiente. A coluna 2 ilustra o efeito do tempo quando ocorre um descarte incorreto de pilhas e baterias. As amostras da coluna 2 apresentaram cor rósea intensa logo no início da coleta, devido ao metal se encontrar em forma disponível (iônica).

Durante a realização da feira de ciências, os alunos utilizaram recursos de apresentação multimídia com o auxílio do projetor de slides, cartazes e as colunas de solo no processo de lixiviação. A composição de pilhas e baterias, descarte incorreto, impactos ambientais por metais e toxicidade foram os principais assuntos abordados durante o experimento e realização da feira.

\section{Conclusão}

O presente estudo mostra de forma contextualizada como as pilhas e baterias podem contaminar o meio ambiente. A partir da montagem das colunas de solo e acompanhamento de todo o experimento por meio da identificação do níquel lixiviado foi possível explorar os conteúdos básicos, além de estimular os alunos a avaliar o risco que é descartar rejeitos de pilhas e baterias no solo. $O$ estudo não só revelou a lixiviação disponibilizando os metais contidos nas pilhas e baterias, com abordagem de cunho CTSA, como também despertou nos alunos, autonomia mediante 0 pensar, com enfoque em problemas ambientais.

\section{Agradecimentos}

Ao PIBID e a CAPES pelo apoio financeiro.

\section{Referências}

[1] MARCONDES, M. E. R. Proposições metodológicas para o ensino de química: oficinas temáticas para a aprendizagem da ciência e o desenvolvimento da cidadania. Uberlândia. v. 7, p. 67-77, 2008.
[2] SANTOS, W. L. P. DOS, MÓL, G. S., SILVA, R. R., CASTRO, E. N. F. DE, SILVA, G DE S., MATSUNAGA, R. T., SANTOS, S. M. DE O., DIB, S. M. F., Química e sociedade: um projeto brasileiro para o ensino de química por meio de temas CTS. Educación Química. v. 3, p. 20-28, 2009.

[3] Parâmetros Curriculares Nacionais: Ensino Médio. Ministério da Educação. Secretaria de Educação Média e Tecnológica. Brasília, Brasil. Disponível em: http://portal.mec.gov.br/ . Acesso em: 17 Maio de 2019.

[4] FRISON, M. D., PINO, J. C. D. CERETTA, J. P. Algumas questões ambientais permeando a construção de propostas de inovação curricular para o ensino de Química. Revista Eletrônica do Mestrado em Educação Ambiental. ISSN 1517-1256, v.23, p. 440-457, 2009.

[5] Resolução № 420 do Conselho Nacional de Meio Ambiente (CONAMA), de 28/12/2009, Diário Oficial da União, 30/12/2000.

[6] BOCCHI, N.; FERRACIN, L.C.; BIAGGIO, S.R. Pilhas e baterias funcionamento e impacto ambiental. Química nova na escola, 2011.

[7] MARTINELLI, A. C., BARRADA, R. V., FERREIRA, S. A. D., FREITAS, M. B. J. G., LELIS, M. F. F. Avaliação da lixiviação do cádmio e níquel provenientes da degradação de baterias níquel-cádmio em uma coluna de solo. Química Nova. v. 37, No. 3, p. 465-472, 2014.

[8] GONZALEZ, K. R. Toxicologia do Níquel. Revinter Revista Intertox de Toxicologia Risco Ambiental e Sociedade, v. 9, n. 2, p. 30-54, jun. 2016.

[9] BRUM, Z. R. Educação ambiental no uso e descarte de pilhas e baterias. Especialização em Educação Ambiental. Universidade Federal de Santa Maria, RS.

[10] DORNFELD, C. B; MALTONI, K. L. A feira de ciências como auxílio para a formação inicial de professores de ciências e biologia. Revista Eletrônica de Educação, v. 5, n. 2, p. 42-58, 2011.

[11] MEZZARI, S.; FROTA, P. R. O.; MARTINS, M. C. Feiras multidisciplinares e o ensino de ciências. Revista Electrónica de Investigación y Docencia (REID), Número Monográfico, p 107-119, 2011.

[12] HARTMANN, A. M; ZIMMERMANN, E. Feira de ciências: a interdisciplinaridade e a contextualização em produções de estudantes do ensino médio. VII Encontro Nacional de Pesquisa em Educação em Ciências. Florianópolis, 2009.

[13] BACCAN, N. et al. Introdução à semimicroanálise qualitativa. 2 ed. São Paulo: Editora da Unicamp: 1988. 